\title{
ON THE UTILITY OF AN IN-CORE FAST NEUTRON GENERATOR
}

\author{
CATHY M. WYSOCKI* and HENRY C. GRIFFIN \\ Department of Chemistry, University of Michigan, Ann Arbor, Michigan 48109, U.S.A.
}

Received 27 October 1977

An examination of the flux magnitudes reported for a LiOD- $\mathrm{D}_{2} \mathrm{O}$ converter (thermal to $14 \mathrm{MeV}$ neutrons) indicates that such a device offers little if any advantage over fission spectrum neutrons.

Fast neutrons are useful for activation analysis of several light elements. For example, oxygen analyses are routinely made in our reactor laboratory and elsewhere by the ${ }^{16} \mathrm{O}(\mathrm{n}, \mathrm{p}){ }^{16} \mathrm{~N}$ reaction. The threshold for this reaction is over $10 \mathrm{MeV}$. Napier et al. $\left.{ }^{1}\right)$ have described a device which was intended to convert thermal neutrons into $14 \mathrm{MeV}$ neutrons by the reaction sequence

${ }^{6} \mathrm{Li}(\mathrm{n}, \alpha){ }^{3} \mathrm{H} \quad \ldots{ }^{2} \mathrm{H}\left({ }^{3} \mathrm{H}, \mathrm{n}\right){ }^{4} \mathrm{He}$,

in a solution of $\mathrm{LiOD}$ in $\mathrm{D}_{2} \mathrm{O}$. They reported a conversion efficiency of $1.9 \times 10^{-4} 14 \mathrm{MeV}$ neutrons per thermal neutron absorbed. This efficiency is similar to that which Frigerio ${ }^{2}$ ) reported for ${ }^{6} \mathrm{LiD}$ solid but nearly ten times his value for ${ }^{6} \mathrm{LiOD} \cdot \mathrm{D}_{2} \mathrm{O}$ solid.

For the purpose of evaluating a thermal-to-14$\mathrm{MeV}$ converter, the primary interest is in the relative total fluxes of thermal neutrons $(<0.2 \mathrm{eV})$ and fast neutrons $(>0.5 \mathrm{MeV})$ as well as the energy distribution of fast neutrons. Characterization of the total reactor-neutron spectrum in terms of thermal, epithermal, and fast regions is amply detailed elsewhere, for example by Erdtmann ${ }^{3}$ ). In a core position near a fuel element the fast/thermal ratio is roughly unity and the Watt expression $\mathrm{e}^{-E} \sinh (2 E)^{\frac{1}{2}}$ is a fairly good approximation to $\phi(E)$ for $E>1 \mathrm{MeV}$. These specifications imply that useful fluxes of fast neutrons are normally present in core positions (see fig. 1). In fact, measurements ${ }^{4}$ ) of the spectrum of reactor neutrons out to $20 \mathrm{MeV}$ indicate the Watt expression underestimates fluxes at high energies.

Napier et al. ${ }^{1}$ ) inferred fluxes from each of four threshold detectors and interpreted the total yield of the ${ }^{14} \mathrm{~N}(\mathrm{n}, 2 \mathrm{n}){ }^{13} \mathrm{~N}$ reaction in terms of $14 \mathrm{MeV}$ neutrons produced by the converter. The ratios of

\footnotetext{
* Engineering and Research Staff, Ford Motor Company.
}

these fluxes to the thermal flux are plotted in fig. 1 at energies corresponding to effective thresholds $^{5,6}$ ) for a Watt distribution. Unfortunately it is impossible to reconcile their results for the various reactions with a fission spectrum either with or without additional $14 \mathrm{MeV}$ neutrons; cross sections and other important assumptions are not given ${ }^{1}$ ). However, the fluxes reported for reactions with ${ }^{28} \mathrm{Si}$ and ${ }^{14} \mathrm{~N}$, relative to each other and to the thermal flux, are consistent with a normal reactor spectrum. Thus the measurements of Napier et al. $\left.{ }^{1}\right)$ do not constitute a determination of the conversion efficiency except to show that the converter is rather ineffective.

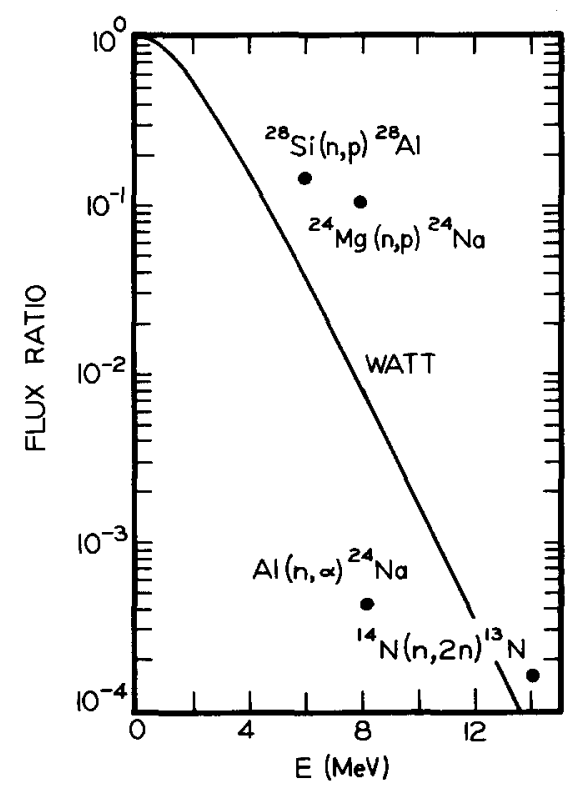

Fig. 1. Fast neutron distribution based on the Watt expression. The line gives the fraction of the integral fast flux above energy $E$. The data points; which are normalized to the thermal flux, are explained in the text. 


\section{References}

1) B. A. Napier, J. P. Holland, S. D. Howe, W. J. Mikols, E. F. Glynn, J. F. Merklin and N. D. Eckhoff, Nucl. Instr. and Meth. 138 (1976) 463.

2) N. A. Frigerio, ANL-7870 (1971) p. 10.
3) G. Erdtmann, Neutron activation tables (Verlag Chemie, Weinheim, 1976).

4) G. G. Sherwood and J. S. King, Trans. Am. Nucl. Soc. 10 (Nov. 1976) 555

5) K. H. Beckurts and K. Wirtz, Neutron physics (Springer-Verlag, New York, 1964).

6) ASTM E 261-70, Am. Soc. Testing Mats. (1975) p. 745 